\title{
Work environment factors in coping with patient death among Spanish nurses: a cross-sectional survey*
}

\author{
Maria Povedano-Jimenez ${ }^{1}$ \\ (D) https://orcid.org/0000-0002-0472-5733 \\ Genoveva Granados-Gamez² \\ (D) https://orcid.org/0000-0001-9933-5422 \\ Maria Paz Garcia-Caro ${ }^{1}$ \\ (D) https://orcid.org/0000-0002-2763-2572
}

Objective: to explore self-perception competence among Spanish nurses dealing with patient death and its relationship with work environment, evidence-based practice, and occupational stress. Method: a cross-sectional web-based survey collected information from a convenience sample of 534 nurses from professional Spanish Colleges who answered four validated questionnaires: Coping with Death Scale, Practice Environment Scale of the Nursing Work Index, Perception of Evidence-Based Practice (EBP) and Nursing Stress Scale. Results: a total of $79 \%$ of the participants were women, the average age was 40 years old, $38 \%$ had a postgraduate degree and $77 \%$ worked in public health settings. Many nurses evaluated their work environment as unfavorable $(66 \%)$, reported high occupational stress (83.5 \pm 14.9$)$, and

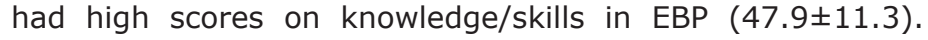
However, $61.2 \%$ of them perceived an optimal coping ( $>157$ score). The multivariate logistic model indicated positive associations with work environment and EBP characteristics (OR: 1.30, $p=0.054$; OR: 1.04, $p=0.007$; OR: 1.13, $p<0.001$, respectively) but negative associations with occupational stress and short work experience (OR: 0.98, $p=0.0043$; OR: $0.74, p<0.002$, respectively). These factors explained $23.1 \%$ of the coping variance $(p<0.001)$. Conclusion: although most nurses perceived optimal coping, the situation could be enhanced by modifying several contextual factors. The identification of these factors would improve the quality of end-of-life care by facilitating nursing management.

Descriptors: Coping Skills; Nursing; End-of-life Care; Practice Environment; Evidence-Based Practice; Occupational Stress.

\section{How to cite this article}

Povedano-Jimenez M, Granados-Gamez G, Garcia-Caro MP. Work environment factors in coping with patient death among Spanish nurses: a cross-sectional survey. Rev. Latino-Am. Enfermagem. 2020;28:e3234. [Access †_—_]; Available in: DOI: http://dx.doi.org/10.1590/1518-8345.3279.3234. 


\section{Introduction}

Regardless of the field of professional care, a dying patient is an emotionally difficult phenomenon ${ }^{(1)}$ that can influence how professionals cope with death. Thus, nurses must feel confident about not only their ability to effectively take care of dying patients ${ }^{(2)}$ but also their ability to maintain their own well-being ${ }^{(1)}$. Skills for coping with patients' death and favorable work-environment conditions are associated with the quality of end-of-life care. These skills are essential to reduce dissatisfaction and stress $^{(3)}$

Some authors ${ }^{(4)}$ refer to the complex multimorbidity during end-of-life care, while others ${ }^{(2)}$ state that hospital management does not commit to the necessary strategies to ensure that nurses feel they are able to face this aspect of their work without difficulty. Therefore, to improve end-of-life care, it is important to know the professionals' perception of coping with death, attitudes about the use of research, characteristics of the work environment ${ }^{(5)}$, and the degree of stress experienced during end-of-life care.

Nurses may express a variety of emotions and attitudes related to end-of-life care $^{(1,6)}$, which are particularly stressful because they are constantly interpreting grief or death as a personal failure ${ }^{(7)}$. Some authors ${ }^{(8)}$ stated that nurses require a wide range of skills to properly deal with death and manage their own fears, beliefs, and attitudes towards dying patients ${ }^{(9)}$.

Inadequate coping with death decreases job satisfaction $^{(10)}$ and increases nurses' stress, negatively affecting the quality of care ${ }^{(11)}$. Meanwhile, individuals who perceive themselves as optimally coping with death often assess these difficult situations as challenges and actively face occupational stress ${ }^{(12)}$.

Occupational stress in palliative care is identified as the combination of the problems involved in caring for others, the lack of self-care strategies, and organizational factors $^{(13)}$. In addition, health professionals tend to have high occupational stress rates in situations of greater clinical demand, long working hours, and poor manager support ${ }^{(5)}$, while a favorable work-environment is essential to minimize the negative impact of working with dying patients ${ }^{(14)}$.

Previously, specialized nurses in emergency and palliative-care settings were a strong predictor of the perception of coping during end-of-life care(6). Today, special interest is growing in experiential learning because constant exposure to the process of dying helps nurses learn about the care of terminal patients ${ }^{(15)}$. Insufficient nursing knowledge of research(16) was improved by educational projects and evidence-based practice guides for the care of dying patients and their families ${ }^{(17)}$. Barriers such as gaps in the knowledge of research and the feeling of a lack of support and leadership on the part of nurses make it difficult to implement evidence-based care in practice ${ }^{(18)}$.

Specifically, intensive-care professionals recognize the lack of end-of-life education and training as an obstacle to quality care ${ }^{(19)}$. The health institutions ${ }^{(20)}$ and the increased awareness among palliativecare professionals are the most influential forces for overcoming barriers in the use and development of research with regard to clinical nursing and, thus, improving end-of-life care. Evidence is available concerning the influence of the practice environment, occupational stress, and evidence-based practice in endof-life care. Thus, knowing whether these factors are related to nurses' perception when coping with dying patients can be central for nursing managers to minimize the emotional impact(21) and promote high-quality endof-life care. However, no studies were found on whether all nursing staff members' perceptions of these factors were associated with coping with death. The aim of the present study is to explore self-perception competence among Spanish nurses dealing with patient death and its relationship with work environment, evidence-based practice, and occupational stress.

\section{Method}

A cross-sectional study was designed to include all the professional registered nurses (RN) in any of the Professional Spanish Colleges of Nursing, employed in different institutions (general healthcare settings, ICU, primary health, palliative care, emergency, surgery, psychiatric units, etc.) with different complexities of care. These Professional Colleges are associations of professionals protected by State Law and recognized by public and private institutions that represent and defend the professional interests of the members.

The recruitment was made using nonrandomized convenience sampling through all Professional Spanish Colleges of Nursing after the study was approved by the regional Bioethics Committee and the Research Committee of the Professional College of Nursing. All the registered nurses received a letter of invitation to participate in the study, as well as the instructions to fill out the set of self-administered questionnaires. The inclusion criteria were as follows: to be a nurse currently belonging to a Professional Spanish College of Nursing, to be able to read and write Spanish and to have access to the Internet. Informed consent was required from all the participants. The sample size was based on the total Spanish RN population $(274,817)$ as of 31 December 2014 (Spanish National Institute of Statistics), resulting in a Type I error of $5 \%$ (step up of 384 participants). A final sample included 534 nurses who answered the online surveys. 
After being given access to the detailed information of the study, nurses gave their written informed consent and participated individually and anonymously. They provided data through a set of questionnaires on Google Drive between February 2014 and April 2015.

All the administrators of the Professional Colleges of Nursing agreed to provide the link to the online survey website. The study followed the principles of the Declaration of Helsinki and was approved by all the ethics committees of Professional College of Nursing.

Participants provided sociodemographic information. Demographic and work-related data included age, sex, educational level (graduate and postgraduate degree), years of nursing practice, work setting [primary and home care, general hospitalization unit (e.g., internal medicine and surgery) and/or specialized (e.g., oncology, gynecology, pediatrics) and critical care and emergency], and type of health center (public, private or co-public). In addition, they completed four specific questionnaires related to their self-perceived professional competence in dealing with death: the Coping with Death Scale, Practice Environment Scale of the Nursing Work Index, Perception of Evidence-Based Practice and Nursing Stress Scale, as follows:

A. Coping with Death Scale (CDS) ${ }^{(22)}$ : This scale characterizes the self-perceived level of coping with dying patients. We used the Spanish version(23) that was previously validated among Spanish palliative care professionals ${ }^{(24)}$ and consists of 30 items scored on a 7 -point Likert-type scale [from 1 (totally disagree) to 7 (totally agree)], with a score range of 30 to 210 . A total score lower than 105 indicates inadequate coping, while a score greater than 157 represents optimal coping(23). A Cronbach's alpha value of 0.824 was previously reported among Spanish nursing students ${ }^{(23)}$.

B. Practice Environment Scale of the Nursing Work Index (PES-NWI): This questionnaire, previously validated in Spanish nurses working in a clinical practice context (with a Cronbach's alpha of 0.90)(25), was used to characterize the nature of professional nursing practice in the original magnet hospitals. This scale consists of a total of 32 items classified into five subscales: 1) "nurse participation in hospital affairs" (8 items); 2) "nursing foundations for quality of care" (9 items); 3) "nurse manager ability, leadership and support of nurses" (4 items); 4) "staffing and resource adequacy" (4 items); and 5) "interprofessional relations and joint practice" (7 items). All items can be answered on a Likert-type scale [from 1 (strongly disagree) to 4 (strongly agree)]. Each subscale score was calculated as the average of the subscale item responses. Moreover, the total PES-NWI score was calculated as the mean of the five subscale scores. Values above 2.5 on at least four out of the five subscales account for "favorable", "mixed" is represented by scores $\geq 2.5$ on two subscales and "unfavorable" is represented by scores $\geq 2.5$ on one subscale or no subscales(26).

\section{Perception of Evidence-Based Practice} Questionnaire (EBPQ): Professional skill at using better knowledge for decision making was addressed by the Spanish version of the Evidence-Based Practice (EBP) questionnaire ${ }^{(27)}$ that consists of 19 items structured into three subscales: 1) "practice of EBP" (6 items); 2) "attitude towards EBP" (3 items) and 3) "knowledge/ skills associated with EBP" (10 items)(28). Cronbach's alpha was 0.87 for Spanish clinical nurses, 0.929 for the practice subscale, 0.722 for the attitude subscale, and 0.916 for the knowledge/skills subscale ${ }^{(27)}$. All items are evaluated from 1 (totally disagree) to 7 (totally agree) score. High scores indicate more positive attitudes and greater use and knowledge of clinical effectiveness and EBP.

D. Nursing Stress Scale (NSS): The Nursing Stress Scale questionnaire assesses and detects different potentially stressful situations in nursing ${ }^{(29)}$. The validated Spanish version, with good reliability (Cronbach's a value of 0.89$)^{(30)}$, was used. This scale consists of 34 items with four possible answers ( $1=$ never to 4 = very frequently). The total scores ranged from 34 (minimum stress level) to 136 (maximum stress level).

A database was automatically organized after each participant completed the questionnaires on Google Drive. Demographic and work-related factors of the sample were analyzed through descriptive statistics. The interquartile range (IQR) was calculated for the mean of the dimensions evaluated by the scales. The associations between quantitative variables were determined with Pearson's correlation coefficient. Kruskal-Wallis and Mann-Whitney $U$ tests were used to compare variables that did not follow a normal distribution. Simple linear regression was used to analyze the individual predictive value of the evaluated dimensions on the Coping with Death Scale. Finally, multiple linear and logistic regression models were applied using the stepwise procedure to select the best set of predictors of the perception of coping with death. All analyses were performed with a Type I error of $5 \%$ and the associated confidence interval (CI) for each parameter. The data analysis was calculated using the statistical package SPSS version 23 (SPSS Inc., Chicago, IL, USA). 


\section{Results}

The descriptive sociodemographic characteristics of the study population ( $n=534$ nurses), according to their self-perceived professional competence in dealing with death, are shown in Table 1 . The majority of the participants (78.7\%) were female, and the average age was 39.7 years (range 22-65 years); $38 \%$ had more than 21 years of work experience, $66 \%$ had a graduate degree, and most were working in a public health setting $(77 \%)$, mainly in general hospitals (27.7\%) and primary and home-care centers $(27.7 \%)$ (Table 1$)$. More than half of the responder nurses $(61.2 \%)$ reported their perception of their coping with death as optimal ( $>157$ score). Compared with older nurses, young nurses more frequently reported inadequate coping $(p<0.001)$. Moreover, being male, having more years of nursing experience, and working in public health clinical settings were also positively and significantly related to selfperceived coping with death $(p<0.05)$.

Many nurses $(66 \%)$ evaluated the quality of their work environment as unfavorable (data not shown), and only one out of the five subscales, "interprofessional relations and joint practice", was perceived as favorable (2.5 $\pm 0.8 ;$ Table 2). Regarding self-rating of the implementation of EBP, the highest score was found in the knowledge/skills subscale $(47.9 \pm 11.3)$. In this respect, the best scores were found among nurses with postgraduate training for the three different factors of the EBP (data not shown), compared with those with less education. Moreover, more than half of the participants also reported high stress levels $(83.5 \pm 14.9)$ during end-of-life care (Table 2).

Table 1 - Sociodemographic characteristics of the participating Spanish nurses recruited between February 2014 and April $2015(n=534)$

\begin{tabular}{|c|c|c|c|c|c|c|c|}
\hline \multirow{2}{*}{ Variables } & \multirow{2}{*}{ n (\%) } & \multicolumn{2}{|c|}{$\begin{array}{l}\text { Coping with } \\
\text { Death Scale }\end{array}$} & \multirow[t]{2}{*}{$\mathbf{p}$} & \multirow{2}{*}{$\begin{array}{l}\text { Inadequate coping } \\
\qquad 105 \\
\mathrm{n}(\%)\end{array}$} & \multirow{2}{*}{$\begin{array}{c}\text { Optimal coping } \geq 157 \\
n(\%)\end{array}$} & \multirow[t]{2}{*}{$\mathrm{p}$} \\
\hline & & Mean & SE $^{*}$ & & & & \\
\hline \multicolumn{8}{|l|}{ Age (years) } \\
\hline$\leq 30$ & $150(28.1)$ & 128.7 & 27.6 & & $41(38.3)$ & $77(23.5)$ & \\
\hline $31-42$ & $162(30.3)$ & 135.8 & 28.0 & $<0.001$ & $35(32.7)$ & $94(28.7)$ & $<0.001$ \\
\hline $43-54$ & $151(28.3)$ & 142.9 & 29.1 & & $27(25.2)$ & $110(33.6)$ & \\
\hline $55-65$ & $71(13.3)$ & 142.1 & 2.9 & & $4(3.7)$ & $46(14.1)$ & \\
\hline \multicolumn{8}{|l|}{ Gender } \\
\hline Male & $114(21.3)$ & 142.6 & 28.4 & 0.006 & $15(14.0)$ & $80(24.5)$ & 0.06 \\
\hline Female & $420(78.7)$ & 135.0 & 28.4 & & $92(85.9)$ & $247(75.5)$ & \\
\hline \multicolumn{8}{|l|}{ Nursing experience } \\
\hline$<10$ years & $214(40.1)$ & 129.9 & 27.0 & $<0.001$ & $56(52.3)$ & $110(33.6)$ & 0.003 \\
\hline $10-20$ years & $118(22.1)$ & 138.2 & 29.3 & & $22(20.6)$ & $76(23.2)$ & \\
\hline$>20$ years & $202(37.8)$ & 142.9 & 28.2 & & $29(27.1)$ & $141(43.1)$ & \\
\hline \multicolumn{8}{|l|}{ Academic degree } \\
\hline Graduate & $354(66.3)$ & 135.1 & 28.4 & 0.038 & $74(69.2)$ & 207 (63.3) & 0.156 \\
\hline Postgraduate & $180(33.7)$ & 139.7 & 28.8 & & $33(30.8)$ & $120(36.7)$ & \\
\hline \multicolumn{8}{|l|}{ Health-care setting } \\
\hline Critical care \& Emergency & $121(22.7)$ & 135.2 & 30.8 & & $32(29.9)$ & $70(21.4)$ & \\
\hline General Hospitalization Unit & $117(21.9)$ & 138.9 & 27.4 & 0.883 & $18(16.8)$ & $75(22.9)$ & 0.532 \\
\hline Specialized Hospitalization Unit & $148(27.7)$ & 137.5 & 28.6 & & $28(26.2)$ & $91(27.8)$ & \\
\hline Primary care & $148(27.7)$ & 135.2 & 27.5 & & $29(27.1)$ & $91(27.8)$ & \\
\hline \multicolumn{8}{|l|}{ Health center } \\
\hline Public & $411(77.0)$ & 138.0 & 28.8 & 0.008 & $77(72.0)$ & $261(79.8)$ & 0.026 \\
\hline Private & $90(16.9)$ & 128.9 & 27.2 & & $26(24.3)$ & $42(12.8)$ & \\
\hline Co-Public & $33(6.2)$ & 141.4 & 26.3 & & $4(3.7)$ & $24(7.3)$ & \\
\hline
\end{tabular}

$*$ SE $=$ Standard Error 
Pearson's correlation showed that age $(r=0.182$, $p<0.001)$, the total score for nursing-practice environment ( $r=0.171, p<0.001)$, and "interprofessional relations and joint practice" subscale $(r=0.172$, $p<0.001$ ) were significantly and positively correlated with coping with death. We also found significant positive correlations with the scores of the three subscales of EBPQ, in favor of nurses with optimal self-perceived professional competence in dealing with dying patients (practice $r=0.262$; attitude $r=0.387$; knowledge/skills $r=0.240 ; \quad p<0.001)$. However, occupational nursing stressful situations and coping with death showed a significant and negative relationship $(r=-0.240, p<0.001)$ as did occupational stress and the work environment $(r=-0.341, p<0.001)$. Positive and significant relationships were also found between the characteristics of the work environment and EBP, highlighting "nursing foundations for quality of care" with practice $(r=161, p<0.001)$ and attitude towards $\operatorname{EBP}(r=0.114, p<0.01)$ (data not shown).

The multivariate comparison of the PES-NWI factors indicated a significant effect of coping with death $\left(F_{10}\right.$; $\left.{ }_{1056}=2.481 ; p=0.006 ; \eta^{2}=0.023\right)$. Participants with perceptions of inadequate ability to cope with death scored lower on "staffing and resource adequacy" (1.7 $\pm 0.6)$ than participants with neutral or optimal selfperceived professional competence in dealing with death $(2.0 \pm 0.7)$. The multivariate comparison of the
EBP factors also showed a significant effect on selfperceived professional competence in dealing with death $\left(F_{6} ; 1060=13.317 ; p<0.001 ; \eta^{2}=0.070\right)$. Those participants with optimal perceived ability to cope with death scored higher on all EBP factors and reported less stress $(81.1 \pm 15.1)$ than did participants with inadequate or neutral perceived ability to cope with dying patients (Table 3 ).

The multivariate regression models, after the application of the variable selection method stepwise predictors, showed that some socio-demographic and work environment characteristics, as well as EBP and occupational stress, were related to coping with death, although only explaining $23.1 \%$ of the coping variance $(p<$ 0.001 ) (Table 4). The multivariate linear regression model indicated positive associations with work environment and EBP characteristics $(\beta=0.12, p<0.05 ; \beta=0.16, p=0.001$; $\beta=0.29, p=0.001$, respectively) but negative associations with occupational stress $(\beta=-0.10, p<0.015)$. A positive attitude towards EBP was the factor with the greatest predictive capacity $(\beta=0.29, p=0.001)$, indicating that a higher score on this factor predicts a higher score on coping with death. In addition to nursing occupational stress, short working experience also showed a negative slope, with scoring lower with regard to perceived coping with death associated with less than 10 years of nursing practice $(\beta=-0.18, p<0.001)$. associated with less than 10 years of nursing practice $(\beta=-0.18, p<0.001)$.

Table 2 - Scale and subscale scores from the Coping with Death, PES-NWI*, EBPQ ${ }^{+}$and Nursing Stress questionnaires among the participating Spanish nurses recruited between February 2014 and April 2015 ( $n=534$ )

\begin{tabular}{|c|c|c|c|c|}
\hline Questionnaire variables & $\mathbf{M}^{\ddagger}$ & $S E^{\S}$ & & \\
\hline Coping With Death overall score & 136.7 & 28.6 & 134.2 & 139.1 \\
\hline Inadequate coping $(n=107)$ & 95.3 & 10.7 & 93.3 & 97.4 \\
\hline Optimal coping $(n=327)$ & 155.3 & 16.8 & 153.6 & 157.3 \\
\hline PES-NWI* overall score & 2.2 & 0.5 & 2.2 & 2.3 \\
\hline Professional participation in matters of the institution & 2.1 & 0.6 & 2.0 & 2.1 \\
\hline Nursing foundation of the quality of care provided & 2.4 & 0.6 & 2.4 & 2.5 \\
\hline Leadership and support to nursing professionals by nurse managers & 2.2 & 0.8 & 2.2 & 2.3 \\
\hline Size of staff and adequacy of human resources & 2.0 & 0.7 & 1.9 & 2.0 \\
\hline Interprofessional relations and joint practice & 2.5 & 0.8 & 2.5 & 2.6 \\
\hline \multicolumn{5}{|l|}{$\mathrm{EBPQ}^{+}$} \\
\hline Practice of EBP $\pi$ & 26.6 & 7.1 & 26.0 & 27.2 \\
\hline Attitude towards EBPף & 16.8 & 3.7 & 16.5 & 17.2 \\
\hline Knowledge/Skills associated with EBPף & 47.9 & 11.3 & 46.9 & 48.8 \\
\hline Nursing Stress Scale & 83.5 & 14.9 & 82.2 & 84.7 \\
\hline
\end{tabular}

*PES-NWI = Practice Environment Scale of the Nursing Work Index; ${ }^{\dagger} \mathrm{EBPQ}=$ Questionnaire on the Perception of Evidence-Based Practice; ${ }^{\ddagger} \mathrm{M}=\mathrm{Mean} ;{ }^{\S} \mathrm{SE}$ = Standard Error; "IQR = Interquartile Range; "EBP = Evidence-based Practice 
Table 3 - Associations between coping with death and PES-NWI*, EBPQ ${ }^{+}$and Nursing Stress questionnaires, among the participating Spanish nurses, recruited between February 2014 and April $2015(n=534)$

\begin{tabular}{|c|c|c|c|c|c|c|c|}
\hline \multirow[t]{2}{*}{ Variables } & \multicolumn{2}{|c|}{$\begin{array}{c}\text { Inadequate coping } \\
(<33) \\
N=107\end{array}$} & \multicolumn{2}{|c|}{$\begin{array}{c}\text { Optimal coping } \\
(>66) \\
N=327\end{array}$} & \multicolumn{3}{|c|}{ F Test ${ }^{\S}$} \\
\hline & Mean & $\mathrm{SE}^{\ddagger}$ & Mean & $\mathrm{SE}^{\ddagger}$ & $F_{2 ; 531} \S$ & $\mathbf{p}^{\| \prime}$ & $\eta^{2 \pi}$ \\
\hline Age & 36.3 & 10.5 & 40.9 & 11.3 & 6.529 & 0.002 & 0.024 \\
\hline PES-NWI* overall score & 2.1 & 0.5 & 2.3 & 0.5 & 9.433 & $<0.001$ & 0.034 \\
\hline Professional participation in matters of the institution & 1.9 & 0.6 & 2.1 & 0.6 & 4.950 & 0.007 & 0.018 \\
\hline Nursing foundation of the quality of care provided & 2.3 & 0.5 & 2.5 & 0.6 & 5.534 & 0.004 & 0.020 \\
\hline $\begin{array}{l}\text { Leadership and support to nursing professionals by } \\
\text { nurse managers }\end{array}$ & 2.0 & 0.7 & 2.3 & 0.8 & 6.148 & 0.002 & 0.023 \\
\hline Size of staff and adequacy of human resources & 1.7 & 0.6 & 2.0 & 0.7 & 6.309 & 0.002 & 0.023 \\
\hline Interprofessional relations and joint practice & 2.3 & 0.7 & 2.6 & 0.8 & 8.215 & $<0.001$ & 0.030 \\
\hline \multicolumn{8}{|l|}{ EBPQ } \\
\hline Practice of EBP** & 24.4 & 6.9 & 27.7 & 6.9 & 10.290 & $<0.001$ & 0.037 \\
\hline Attitude towards EBP** & 14.5 & 4.6 & 17.8 & 2.8 & 38.960 & $<0.001$ & 0.128 \\
\hline Knowledge/Skills associated with EBP ${ }^{* *}$ & 44.4 & 12.3 & 49.7 & 10.7 & 11.446 & $<0.001$ & 0.041 \\
\hline Nursing Stress Scale & 88.4 & 12.3 & 81.1 & 15.1 & 11.826 & $<0.001$ & 0.043 \\
\hline
\end{tabular}

*PES-NWI = Practice Environment Scale of the Nursing Work Index; ${ }^{+} \mathrm{EBPQ}=$ Questionnaire on the Perception of Evidence-Based Practice; ${ }^{\ddagger}$ SE $=$ Standard Error; ${ }^{\mathrm{s} F}$ Test $=$ Value Distribution Test; "p-value; ${ }^{\natural} \eta^{2}=$ Eta-square; $* * E B P=$ Evidence-based Practice

In the same way, when the outcome was dichotomized, the multivariate regression logistic model also showed that some socio-demographic and work environment characteristics, as well as EBP and occupational stress, were related to coping with death (Table 5). Thus, the multivariate model indicated positive associations with work environment (interprofessional relations) and EBP characteristics (practice and attitude) but negative associations with nursing occupational stress. Years of experience and training were also determinant factors of optimally coping with death rather than age. In the logistic model, being a male was not a determining factor of self-perceived professional competence in dealing with death.

Table 4 - Multivariate lineal regression model of Coping with Death Scale (Spanish nurses' study during 2014-2015)

\begin{tabular}{lcccc}
\hline \multicolumn{1}{c}{ Variables } & $\mathbf{B}^{*}$ & $\mathbf{p}^{\dagger}$ & \multicolumn{2}{c}{$95 \% \mathrm{Cl}^{\ddagger}$} \\
\hline Constant & & & 70.61 & 111.95 \\
$\begin{array}{l}\text { Interprofessional relations and joint } \\
\text { practice }\end{array}$ & 0.12 & 0.004 & 1.30 & 6.98 \\
Practice of EBP§ & 0.16 & 0.001 & 0.32 & 0.96 \\
Attitude towards EBP§ & 0.29 & 0.001 & 1.63 & 2.86 \\
Nursing Stress & -0.10 & 0.015 & -0.35 & -0.04 \\
Sex (male) & 0.07 & 0.052 & -0.03 & 10.46 \\
Prof Exp (<10 years) & -0.18 & 0.001 & -15.72 & -5.68 \\
Prof Exp (10-20 years) & -0.05 & 0.277 & -8.92 & 2.56 \\
\hline
\end{tabular}

${ }^{*} \mathrm{~B}=$ Beta $;{ }^{\dagger} \mathrm{p}$ value $;{ }^{\ddagger} \mathrm{CI}=$ Confidence Interval; ${ }^{\mathrm{s}} \mathrm{EBP}=$ Evidence-based Practice
Table 5 - Multivariate regression logistic model of Coping with Death Scale (Spanish nurses' study during 2014-2015)

\begin{tabular}{lcccc}
\multicolumn{1}{c}{ Variables } & OR $^{*}$ & $\mathbf{p}^{\dagger}$ & \multicolumn{2}{c}{$95 \% \mathrm{Cl}^{\ddagger}$} \\
\hline Constant & & & 0.075 & 4.981 \\
$\begin{array}{l}\text { Interprofessional relations } \\
\text { and joint practice }\end{array}$ & 1.30 & 0.054 & 0.995 & 1.698 \\
Practice of EBP§ & 1.04 & 0.007 & 1.011 & 1.072 \\
Attitude towards EBP§ & 1.13 & 0.000 & 1.068 & 1.189 \\
Nursing Stress & 0.98 & 0.043 & 0.971 & 0.999 \\
Sex (male) & 1.47 & 0.148 & 0.873 & 2.463 \\
Prof Exp (<10 years) & 0.74 & 0.002 & 0.295 & 0.760 \\
Prof Exp (10-20 years) & 0.61 & 0.295 & 0.428 & 1.294 \\
\hline
\end{tabular}

*OR = Odds Ratio; ${ }^{\dagger} \mathrm{p}$ value; ${ }^{\mathrm{C}} \mathrm{CI}=$ Confidence Interval; ${ }^{\mathrm{S}} \mathrm{EBP}=$ Evidencebased Practice

\section{Discussion}

In our study population, the findings relate several sociodemographic and occupational characteristics to the nurses' self-perceived professional competence in dealing with death. Specifically, age (older than 31 years of age), gender (being male), education (postgraduate education training) and work experience (having more than 10 yrs. nursing experience) increased the coping with death score. In addition, the results of the questionnaires implied that four different variables were also important for assessing self-perceived professional competence in dealing with death: 1) collegial nurse-doctor relations related to work environment; 2 ) the individual's attitude towards EBP, which includes perceived barriers such 
as workload and personal judgments; 3) the practice related to the implementation of EBP and to individual patient care; and 4) occupational stress.

Different previous studies have corroborated these findings(31-36). According to these studies, males are rational, decisive, and resilient when working in challenging situations, such as caring for dying patients(31); moreover, males often have their own approach to coping with difficult emotions and maintaining their own well-being because male stereotypes of self-sufficiency and competitiveness influence their practices and experiences ${ }^{(32)}$.

Some studies also emphasize the benefit of having longer nursing experience, fuller training in end-oflife care ${ }^{(33)}$, and exposure to situations of suffering such as dying(34). This provides knowledge and skills for improved coping with dying patients in the future, potentially reaching the point of feeling comfortable(6). Nurses with less than 10 years of experience were more vulnerable and exhausted, had higher levels of depersonalization, and had lower levels of personal fulfillment(35). However, at the same time, nurses with more years of experience were able to keep a distance and set boundaries in end-of-life $\operatorname{care}^{(36)}$. These findings also fit with previous evidence pertaining to "interprofessional relations and joint practice"(34).

In relation to the perception among Spanish nurses concerning their work environment, twothirds of the study population considered the work environment unfavorable because their evaluations were lower than the magnet hospital scores. However, the EBP was assessed according to the nurses' knowledge more than their practice, indicating a discouraging work context. Regarding factors least valued within the PES-NWI scale, a personnel shortage is a restrictive element to fulfilling professional roles and responsibilities ${ }^{(37)}$. A supportive work environment among colleagues is helpful in dealing with end-of-life care $^{(38)}$. This perceived unfavorable work environment could also be related to the economic crisis that Spanish health professionals are lately experiencing(39). Additionally, the high workload in dying patient care demands the same conditions of care as before the start of the crisis and has not adapted to the shortage of resources ${ }^{(40)}$. A shortage of staff could force a choice between providing comprehensive care to all dying patients or focusing only on the most urgent $\operatorname{cases}^{(41)}$, causing frustration and emotional exhaustion among professionals ${ }^{(42)}$.

On the other hand, the low scores on the PESNWI subscale "nurse participation in hospital affairs" deserve special attention by healthcare administrators because this professional participation in matters of organizational performance positively influences efficiency and effectiveness at the professional team level ${ }^{(43)}$, and it was observed that more than half of the professionals reported high levels of participation in hospital affairs in the situations posed.

The positive association found between the attitude towards and practice of EBP and the perceived ability to cope with death suggests the importance of having well-founded knowledge of professional safety, that is, to perceive oneself as having the ability to face the death of others. Several studies have indicated that additional training programs help to adequately address dying patients ${ }^{(44)}$. It should be noted that some institutions have managed to bolster the confidence of nurses to provide the best care to oncological patients after going through EBP educational programs ${ }^{(45)}$. However, there are still barriers to the offer of ongoing education for nurses participating in end-of-life care ${ }^{(10)}$.

The negative association between occupational stress and ability to cope with death, regardless of the nursing workplace, appeared in previous findings ${ }^{(38,46)}$, indicating that compassion fatigue limits coping with the final moments of a patient's life.

Finally, our findings corroborate the relationship between the dimensions of the professional context analyzed and the ability to cope with death. Specifically, it was found that the worst scores in all dimensions of the context analyzed were related to the lowest level of the ability to cope with death; however, not all of the dimensions analyzed had the same predictive value for self-perceived competence dealing with death. The model of predictors showed that the following factors influenced the nurses' ability to cope with dying patients, with moderate explanatory power: sex (male), nursing experience (less than 10 years and between 10 and 20 years), "collegial nurse-doctor relations", the perception of the work-environment, practice factors, attitude towards EBP and nursing stress. Several studies have noted that the positive association found between interprofessional relations and joint practice and the nurse's self-perceived professional competence in dealing with death was the main source of emotional support for improving nurse care for dying patients ${ }^{(46-48)}$. 
This study has several shortcomings and strengths. It has an observational design, so we could not definitively establish causal relationships. Although the study population could be considered representative of the Spanish population (a country and a culture), the recruitment system limited any generalization. Most of the participants were female, which is in line with the gender distribution in the Spanish nursing profession. All the questionnaires used were validated but may have led to a bias in information gathering due to a lack of knowledge or other unidentified factors. Additionally, the questionnaires were completed online, restricting the web survey to the nurses who had internet access. Nevertheless, these questionnaires have been used in numerous studies among the Spanish population to reduce information bias. The sample size was large, the study subjects were from different regions of Spain, and many distinct factors were considered simultaneously. We should also highlight that to minimize selection bias, the study was performed not only in palliative care or oncology but also in other nursing specialties.

According to our results, this type of survey should be used to detect which nurses may perceive high levels of self-competence in end-of-life care. It is important that nursing professionals become comfortable with dying patients in their work, which implies that attitudes, social awareness, or personal opinions may also influence coping strategies. Moreover, healthcare institutions must be involved to identify the factors that influence the quality of life of the health professional and, therefore, the quality of their practice. Nursing education should also promote specific training to reinforce coping strategies at the end of life or the management of feelings towards the patient who will die to avoid negative influences on the work of future professionals.

\section{Conclusion}

Despite the challenges that a nurse faces in an environment with dying patients, this situation has not been a determinant for the optimal level of perceived ability to cope with death. The determining factors are age, years of experience and training. In a predominantly female environment, being male proves to be a determining factor of an optimal ability to cope with death and one of the factors that predicts the self-perceived professional competence in dealing with death. Future studies should thoroughly analyze these gender differences. All the elements of the professional context analyzed were found to influence the level of the nurses' ability to cope with death; however, the moderate explanatory power suggests the need to consider other elements not considered in this study. Finally, given the importance of the professional team, the nursing administration plays a key role in providing better practice environments, by facilitating the use and training of research in the workplace and identifying occupational stress.

\section{Acknowledgments}

We sincerely thank all participants for responding to the questionnaires and sharing their points of views.

\section{References}

1. Zheng RS, Guo QH, Dong FQ, Owens RG. Chinese oncology nurses'experience on caring for dying patients who are on their final days: a qualitative study. Int J Nurs Stud. [Internet] 2015 [cited Jul 28, 2018]; 52(1):288-96. Available from: https://doi. org/10.1016/j.ijnurstu.2014.09.009

2. Liu YC, Chiang HH. From vulnerability to passion in the end-of-life care: The lived experience of nurses. Eur Oncol Nurs Soc. [Internet] 2017 [cited Ago 15, 2018]; 31:30-6. Available from: http://dx.doi.org/10.1016/j. ejon.2017.09.002.

3. Aiken LH, Sloane DM, Bruyneel L, Van den Heede K, Sermeus W. Nurses' reports of working conditions and hospital quality of care in 12 countries in Europe. Int ] Nurs Studies. [Internet] 2013 [cited Ago 12, 2018]; 50(2):143-53. Available from: http://dx.doi. org/10.1016/j.ijnurstu.2012.11.009

4. Lai XB, Wong FKY, Ching SSY. The experience of caring for patients at the end-of-life stage in non-palliative care settings: a qualitative study. BMC Palliative Care. [Internet] 2018 [cited Sep 3, 2018]; 17(1):116. Available from: http://dx.doi.org/10.1186/s12904-018-0372-7.

5. Baartman LKJ, de Bruijn E. Integrating knowledge, skills and attitudes: Conceptualising learning processes towards vocational competence. Educ Res Rev. [Internet] 2013 [cited Sep 3, 2018]; 6(2):125-34. doi: 10.1016/j. edurev.2011.03.001.

6. Peters L, Cant R, Payne S, O'Connor M, McDermott $\mathrm{F}$, Hood $\mathrm{K}$ et al. Emergency and palliative care nurses' levels of anxiety about death and coping with death: A questionnaire survey. Austr Emerg Nurs J. [Internet] 2013 [cited Ago 18, 2018]; 16(4):152-9. Available from: https://doi.org/10.1016/j.aenj.2013.08.001 
7. Barnett MD, Moore JM, Garza CJ. Meaning in life and self-esteem help hospice nurses withstand prolonged exposure to death. J Nurs Manage. [Internet] 2019 [cited Ago 8, 2018]; 27(4):775-80. doi: 10.1111/jonm.12737. 8. Souza e Souza LP, Ribeiro JM, Rosa RB, Gonçalves RCR, Oliveira e Silva CS, Barbosa DA. La muerte y el proceso de morir: sentimientos manifestados por los enfermeiros. Enferm Global. [Internet] 2013 [cited Sep 27, 2018]; 12:222-9. Available from: https://doi. org/10.6018/eglobal.12.4.163241

9. Celma AG, Strasser G. Dying process and nursing: a relational approach. Theoretical reflections on assistance dealing with death. Physis: Rev Saúde Coletiva. [Internet] 2015 [cited Ago 8, 2018]; 25(2):485-500. Available from: http://dx.doi.org/10.1590/S010373312015000200009

10. Karbasi C, Pacheco E, Bull C, Evanson A, Chaboyer W. Registered nurses' provision of end-of-life care to hospitalised adults: A mixed studies review. Nurse Educ Today. [Internet]. $2018 \mathrm{Dec} ; 71: 60-74$. Available from: http://dx.doi.org/10.1016/j.nedt.2018.09.007.

11. Zambrano SC, Chur-Hansen A, Crawford GB. The experiences, coping mechanisms, and impact of death and dying on palliative medicine specialists. Palliative Supportive Care. [Internet] 2014 [cited Oct 23, 2018]; 12:309-16. doi: 10.1017/S1478951513000138.

12. Terakado A,Matsushima E.Work stres samong nurses engaged in palliative care on general wards. Psychooncology. [Internet]2015[citedMay2,2019];24:63-9. Available from: http://dx.doi.org/10.1002/pon.3584.

13. Beng TS, Chin LE, Guan NC, Yee A, Wu C, Pathmawathi $S$, et al. The experiences of stress of palliative care providers in Malaysia: A thematic analysis. Am J Hospice Palliative Med. [Internet] 2015 [cited Sep 2, 2018]; 32(1):15-28. Available from: http://dx.doi.org/10.1177/1049909113503395

14. Anderson NE, Kent B, Owens RG. Experiencing patient death in clinical practice: nurses' recollections of their earliest memorable patient death. Int J Nurs Stud. [Internet] 2015 [cited Sep 6, 2018]; 52(3):695-704. Available from: http://dx.doi.org/10.1016/j. ijnurstu.2014.12.005

15. Kopp W, Hanson MA. High-fidelity and gaming simulations enhance nursing education in end-of-life care. Clin Simul Nurs. [Internet] 2015 [cited Sep 6, 2018]; 8(3):e97-e102. Available from: http://dx.doi. org/10.1016/j.ecns.2010.07.005

16. Yoshioka S, Moriyama M, Ohno Y. Efficacy of the End-of-Life Nursing Care Continuing Education
Programfor nurses in general wards in Japan. Am J Hospice Palliative Care. [Internet] 2014 [cited Ago 8, 2018]; 31:513-20. Available from: https://doi. org/10.1177/1049909113491133

17. Stilos K. Improving end-of-life care through quality improvement. Int J Palliative Nurs. [Internet] 2016 [cited Ago 8, 2018]; 22(9):430-4. doi: 10.12968/ ijpn.2016.22.9.430.

18. Skela-Savič B, Pesjak K, Lobe B. Evidence-based practice among nurses in Slovenian Hospitals: a national survey. Int Nurs Rev. [Internet] 2016 [cited Sep 12, 2018]; 63(1):122-31. Available from: https://doi. org/10.1111/inr.12233.

19. Aslakson R, Cheng J, Vollenweider D, Galusca D, Smith TJ, Pronovost P J. Evidence-Based Palliative Care in the Intensive Care Unit: A Systematic Review of Interventions. ] Palliative Med. [Internet] 2014 [cited Jul 9, 2018]; 17(2):219-35. Available from: http:// dx.doi.org/10.1089/jpm.2013.0409

20. Wilson J, Kirshbaum M. Effects of patient death on nursing staff: a literature review. $\mathrm{Br}$ J Nurs. [Internet] 2011 [cited Ago 30, 2018]; 20(9):559-63. doi: 10.12968/bjon.2011.20.9.559.

21. Hopkinson JB, Hallett CE, Luker KA. Everyday death: how do nurses cope with caring for dying people in hospital? Int ] Nurs Stud. [Internet] 2005 [cited Sep 26, 2018]; 42(2):125-33. doi: 10.1016/j. ijnurstu.2004.06.004.

22. Bugen LA. Coping: Effects of death education. Omega: J Death Dying. 1980;11:175-83.

23. Schmidt-RioValle J, Montoya-Juarez R, CamposCalderon CP, Garcia-Caro MP, Prados-Peña D, CruzQuintana F. The effects of a training program on coping with death in palliative care. Med Paliativa. [Internet] 2012 [cited Ago 15, 2018]; 19(3):113-20. doi:10.1016/j.medipa.2010.11.001.

24. Galiana L, Oliver A, De Simone G, Linzitto JP, Benito $E$, Sansó N. A brief measure for the assessment of competence in coping with death: The coping with death scale short version. J Pain Symptom Manage. 2019;57(2):209-15. Available from: http://dx.doi. org/10.1016/j.jpainsymman.2018.11.003.

25. Fuentelsaz-Gallego C, Moreno-Casbas MT, GonzalezMaria E. Validation of the Spanish version of the questionnaire Practice Environment Scale of the Nursing Work Index. Int ] Nurs Stud. [Internet] 2013 [cited Ago 11, 2018]; 50(2):274-80. Available from: http://dx.doi. org/10.1016/j.ijnurstu.2012.08.001 
26. Lake ET, Friese CR. Variations in Nursing Practice Environments: Relation to Staffing and Hospital Characteristics. Nurs Res. [Internet] 2006 [cited Ago 1, 2018]; 55(1):1-9. Available from: https://www.ncbi. nlm.nih.gov/pubmed/16439923

27. Pedro Gómez J, Morales Asencio JM, Sesé Abadc A, Bennasar Venya M, Ruiz Roman MJ, Muñoz Ronda F. Validation of the Spanish Version of the Evidence Based Practice Questionnaire in Nurses. Rev Española Salud Publica. [Internet] 2006 [cited Ago 1, 2018]; 83(4):577-86. Available from: http://scielo. isciii.es/scielo.php?script=sci_arttext\&pid=S113557272009000400009\&Ing=es

28. Upton D, Upton P. Development of an evidencebased practice questionnaire for nurses. J Adv Nurs. [Internet] 2006 [cited Ago 1, 2018]; 53(4):454-8. doi: 10.1111/j.1365-2648.2006.03739.x.

29. Gray-Toft $P$, Anderson J. The nursing stress scale: development of an instrument. J Behav Assess. [Internet] 1981 [cited Sep 2, 2018]; 3:11-23. doi: 10.1007/BF01321348.

30. Mas R, Escribà-Agüir V. The spanish version of the nursing stress scale, a cross-cultural adaptation process. Rev Española Salud Publica. [Internet] 1998 [cited Sep 5, 2018]; 72(6): 529-38. ISSN 2173-9110. Available from: http://scielo.isciii.es/scielo.php?script=sci_ arttext\&pid $=$ S1135-57271998000600006\&lng =es

31. Wu TW, Oliffe JL, Bungay V, Johnson JL. Male ICU Nurses' Experiences of Taking Care of Dying Patients and Their Families: A Gender Analysis. Am J Men's Health. [Internet] 2015 [cited Oct 12, 2018]; 9(1):44-52. Available from: https://doi. org/10.1177/1557988314528236

32. Oliffe JL, Han CSE. Beyond workers' compensation: Men's mental health in and out of work. Am J Men's Health. [Internet] 2014 [cited Oct 8, 2018]; 8(1):45-53. Available from: https://doi.org/10.1177/1557988313490786

33. Ober AM, Granello DH, Wheaton JE. Grief counseling: an investigation of counselors' training, experience, and competencies. J Counsel Develop. [Internet] 2012 [cited Oct 11, 2018]; 90(2):150-9. Available from: https:// doi.org/10.1111/j.1556-6676.2012.00020.x

34. Sansó N, Galiana L, Oliver A, Pascual A, Sinclair $S$, Benito E. Palliative Care Professionals' Inner Life: Exploring the Relationships Among Awareness, Self-Care, and Compassion Satisfaction and Fatigue, Burnout, and Coping With Death. J Pain Symptom Manage. [Internet] 2015 [cited Oct 20, 2018]; 50(2):200-7. Available from: https://doi.org/10.1016/j.jpainsymman.2015.02.013
35. Lobb EA, Oldham L, Vojkovic S, Kristjanson LJ, Smith J, Brown JM, Dwyer VWJ. Frontline grief: the workplace support needs of community palliative care nurses after the death of a patient. J Hospice Palliative Nurs. [Internet] 2010 [cited Oct 16, 2018]; 12(4):225-35. Available from: http://dx.doi.org/10.1097/NJH.0b013e3181dceadc

36. Hindere KA. Reactions to patient death: The lived experience of critical care nurses. DCCN - Dimensions Crit Care Nurs. [Internet] 2012 [cited May 16, 2019]; 31:252-9. Available from: http://dx.doi.org/10.1097/ DCC.0b013e318256e0f1.

37. Bakker AB, Demerouti E. Job demands-resources model. J Work Org Psychol. [Internet] 2013 [cited Oct 23, 2018]; 29:107-15. Available from: http:// dx.doi.org/10.5093/tr2013a16

38. Malloy $\mathrm{P}$, Thrane $\mathrm{S}$, Winston $\mathrm{T}$, Virani R, Kelly K. Do nurses who care for patients in palliative and endof-life settings perform good self-care? J Hospice Palliative Nurs. [Internet] 2013 [cited Oct 26, 2018]; 15(2):99-106. Available from: https://doi.org/ 10.1097/ NJH.0b013e31826bef72.

39. Zabalegui A, Cabrera E. Economic crisis and nursing in Spain. J Nurs Manage. [Internet] 2010 [cited Oct 14, 2018]; 18:505-8. Available from: https://doi. org/10.1111/j.1365-2834.2010.01118.x

40. Fuentelsaz-Gallego C, Moreno T, López D, Gómez T, González E. Perception of work environment of nurses in hospitals of the Spanish national health system. RN4CAST-Spain project. Enferm Clin. [Internet] 2012 [cited Oct 5, 2018]; 22(5):261-8. doi: 10.1016/j. enfcli.2012.09.001.

41. Lemonde $M$, Payman N. Perception du rôle de I'infirmière en oncologie. Can Oncol Nurs J. [Internet] 2015 [cited Nov 2, 2018]; 25(4). Available from: http:// www.canadianoncologynursingjournal.com/index.php/ conj/article/view/610

42. Sundin L, Hochwalder J, Lisspers J. A longitudinal examination of generic and occupational specific job demands, and work-related social support associated with burnout among nurses in Sweden. Work. [Internet] 2011 [cited Oct 4, 2018]; 38(4):389-400. Available from: https://doi.org/10.3233/WOR-2011-1142

43. Adriaenssens J, De Gucht V, Maes S. The impact of traumatic events on emergency room nurses: Findings of a questionnaire survey. Int J Nurs Stud. [Internet] 2012 [cited Oct 6, 2018]; 49:1411-22. Available from: http://dx.doi.org/10.1016/j.ijnurstu.2012.07.003

44. Lindqvist $O$, Tishelman C. Going public: reflections on developing the DöBra research program for health- 
promoting palliative care in Sweden. Progress Palliative Care. [Internet] 2016 [cited Oct 23, 2018]; 24(1):19-24. doi: 10.1080/09699260.2015.1103497.

45. Eaton LH, Meins AR, Mitchell PH, Voss J, Doorenbos AZ. Evidence-Based Practice Beliefs and Behaviors of Nurses Providing Cancer Pain Management: A MixedMethods Approach. Oncol Nurs Forum. [Internet] 2015 [cited Oct 9, 2018];42(2):165-73. Available from: http://dx.doi.org/10.1188/15.ONF.165-173

46. Chang HJ, Hsu LL, Hsieh SI, Chu TL, Yu WP. Development of a Needs Scale for Nurses Receiving InService Palliative Care Education. Cancer Nurs. [Internet] 2016 [cited Oct 9, 2018]; 39(3):22-31. Available from: http://dx.doi.org/10.1097/NCC.0000000000000277

47. Sato M. Nurse experiences of grief and coping in the intensive care unit. [PhD thesis]. Arizona: University of Arizona; 2015.

48. Bohnenkamp S, Pelton N, Rishel CJ, Kurtin S. Implementing Evidence-Based Practice Using an Interprofessional Team Approach: Part Two. Oncol Nurs Forum. [Internet] 2014 [cited Oct 27, 2018]; 41(5):54850. Available from: http://dx.doi.org/10.1188/14.

ONF.548-550 Creative Commons (CC BY).

This license lets others distribute, remix, tweak, and build upon your work, even commercially, as long as they credit you for the original creation. This is the most accommodating of licenses offered. Recommended for maximum dissemination and use of licensed materials. 